\title{
Accommodating Soft Skills in Software Project Management
}

\author{
Aneerav Sukhoo, Andries Barnard, Mariki M. Eloff, \\ John A. Van der Poll \\ University of South Africa, Pretoria, South Africa \\ aneeravsukhoo@yahoo.com barnaa@unisa.ac.za \\ eloffmm@unisa.ac.za vdpolja@unisa.ac.za \\ Mahendrenath Motah \\ University of Technology, Mauritius
}

\section{mmotah@utm.intnet.mu}

\begin{abstract}
Software project management probably is a sector that has witnessed the highest rate of project failure in the world. This is not the case with project management concerned with other disciplines due to better management of their inherent strengths and weaknesses.

Hard skills, often described as a science and comprising processes, tools and techniques applied to projects are the main focus of many project management methodologies. Extensive research has been carried out in the project management domain with greater focus on hard skills. Soft skills described as an art, are very often ignored during software project management. Such skills, acquired through experience, are concerned with managing and working with people, ensuring customer satisfaction and creating a conducive environment for the project team to deliver high quality products within budget and on time and exceeding stakeholder expectations.
\end{abstract}

This paper summarizes the soft skills that can possibly improve the success rate of software projects. These projects, if not managed properly can lead to escalation of budget and time schedules beyond expectations. Deterioration of quality may be inevitable while deploying efforts to deal with cost overrun and schedule extension.

Research in the field of soft skills required has been carried out at the University of Arkansas. The results show that IT organizations are conscious of the need for soft skills. Furthermore, a number of organizations, like Polaris, Sun Microsystems and Mastek have found it necessary to include soft skills in their training agenda.

Keywords: soft skills, hard skills, IT project management, software project management, project management methodology, emotional

Material published as part of this journal, either on-line or in print, is copyrighted by Informing Science. Permission to make digital or paper copy of part or all of these works for personal or classroom use is granted without fee provided that the copies are not made or distributed for profit or commercial advantage AND that copies 1) bear this notice in full and 2) give the full citation on the first page. It is permissible to abstract these works so long as credit is given. To copy in all other cases or to republish or to post on a server or to redistribute to lists requires specific permission from the publisher at Publisher@InformingScience.org intelligence, psychology.

\section{Introduction}

Information Technology (IT) project management (software project management) is a sector that has arguably witnessed the highest rate of project failure in the world. Dorsey (2000) 
pointed out that large information systems projects have been reported to be subject to failure rates between 50-80\% and Bupa (2005) stated that according to a recent report by the Standish Group, only one in three IT projects were delivered on time, within budget and according to specification. This is also confirmed by the CHAOS report (The Standish Group, 2001), which is published annually. This is generally not the case with project management concerned with other disciplines due to better management of inherent strengths and weaknesses. IT projects, particularly those of a software nature, have different strengths and weaknesses as compared to traditional engineering projects (Sukhoo, Barnard, Eloff \& Van der Poll, 2004a). For instance, some strengths associated with software projects include flexibility, ease of creating backups, scalability, replication and reusability of components while some weaknesses include invisibility, complexity, difficulty to add people to delayed projects and the need for regular upgrades.

However, hard skills remain the traditional main focus of most IT project management methodologies. Hard skills, often described as a science (Belzer, 2004), comprise processes, tools and techniques applied to projects. In managing software projects, tools and techniques related to hard skills are given much attention in an attempt to drive projects towards success. Unfortunately, we find that many software projects do not live up to expectations.

Soft skills, often described as an art (Belzer, 2004), have been identified as critical for project success. They are often concerned with managing and working with people (Kirsch, 2004). These skills are typically acquired through experience (Belzer, 2004). Companies, like Mastek, Polaris and Sun Microsystems, being conscious of the importance of soft skills, have incorporated such skills into their training agenda (Arora, 2003).

This paper presents the soft skills that can possibly lead to an improvement of the success rate of software projects. These software projects, if not managed properly can lead to an escalation of budget and time schedules beyond expectations. Deterioration of quality may be inevitable while deploying efforts to deal with cost overruns and schedule extensions.

\section{Motivation for this Research}

Every year, the CHAOS chronicle (see for example The Standish Group, 2001) reports on the failure rate of IT projects in the USA. Although there was an observed decline in the percentage of failed projects in the USA since 1994 as summarized by Sonnekus and Labuschagne (2004), the same trend may not have been observed in other countries, especially those with a developing economy.

Developed countries like the UK and USA are facing an advantageous situation with the use of welladapted methodologies, tools and techniques through rigorous research and development initiatives both from academia as well as from professional bodies like the Project Management Institute (PMI) and Office of Government Commerce (OGC). According to a survey carried out by Sonnekus and Labuschagne

\begin{tabular}{|c|c|}
\hline \multicolumn{2}{|c|}{ Table 1 - USA success rate } \\
\hline Year & $\begin{array}{c}\text { Percentage of failed } \\
\text { projects }\end{array}$ \\
\hline CHAOS - 1994 & $31 \%$ \\
\hline CHAOS - 1996 & $40 \%$ \\
\hline CHAOS - 1998 & $28 \%$ \\
\hline CHAOS - 2000 & $23 \%$ \\
\hline CHAOS - 2002 & $15 \%$ \\
\hline
\end{tabular}
(2004), the failure rate of IT projects in South Africa was found to be $22 \%$, which can be observed to be comparable to that of the CHAOS chronicle released in 2000 (see Table 1).

Following a survey carried out in 2003 in Mauritius (Sukhoo, Barnard, Eloff \& Van der Poll, $2004 \mathrm{~b}$ ), at least $50 \%$ of software projects that suffered due to deadline problem, budget overruns and quality problems were found to be $50 \%, 30 \%$ and $10 \%$ respectively.

In contrast, traditional engineering projects generally achieve much higher success rates. This is due to exploitation of inherent strengths and prudent management of weaknesses associated with 
engineering projects that are different from those of software projects (Sukhoo, Barnard, Eloff \& Van der Poll, 2004a). The strengths and, in particular the weaknesses associated with engineering projects have been addressed better due to the fact that these projects were managed for many decades and are also better understood. Management of software projects in particular has been carried out for far less than what is the case with traditional projects. In addition to hard skills required, it has been observed that a good mix with soft skills is required for IT organizations (Arora, 2003). When popular project management methodologies like the PMBOK ${ }^{\circledR}$ (Project Management Body of Knowledge) and PRINCE 2 (PRojects IN Controlled Environment) are analyzed closely, one finds that not much emphasis is laid on soft skills.

Furthermore, a survey of soft skills required in IT organizations was carried out at the University of Arkansas (Hathaway, 1999) and the results obtained showed highly desired skills to be problem solving process, listening skills, teamwork, adaptability to new technology and new languages, transferring knowledge to application, time management, visualization and conceptualization skills and verbal communication. Desired skills included the ability to multi-task, dealing with business culture, inter-team communication, interpersonal skills, constructive criticism, organisation skills, stress management and general writing skills. According to the survey, less desired skills comprise leadership, technical writing, dealing with diversification (different cultures) and presentation skills.

\section{Hard Skills}

Hard skills are the technical skills required within the confines of a domain. They encompass the following dimensions:

- Processes

- Tools

- Techniques

Aspects pertaining to some of the above may be learnt largely through a formal project management course or from textbooks.

Extensive research has been conducted in project management with greater emphasis on hard skills (Might \& Fisher, 1985; Keil, 1995 as cited in Kirsch, 2004). These skills, although of crucial importance, are to be considered along with the broader soft skills according to Belzer (2004) and Moreira (2004). Most project management methodologies show a greater coverage of hard skills. It is observed that research efforts are expended towards automating the process of management of projects with regards to hard skills.

However, Moreira (2004) claims that success in the management of software projects does not rely entirely on hard skills. A combination of hard skills and soft skills may effectively and efficiently steer projects towards success. This is confirmed by the fact that the best jobs are often offered to seasoned professionals who have a good combination of technical knowledge, general business skills and communication skills (Moreira, 2004).

Given that software projects have inherent complexity and invisibility features (Hughes \& Cotterell, 2002) that may hamper progress during development stages, it becomes necessary to articulate hard skills together with soft skills.

\section{Soft Skills}

Soft skills are the non-technical skills that are often not given due consideration while managing projects. Soft skills, often described as an art (Belzer, 2004), is concerned with managing and working with people, ensuring customer satisfaction with the intention of retaining them and cre- 
ating a conducive environment for the project team to deliver high quality products within budget and on time and exceeding stakeholders expectations. Soft skills are acquired through experience, but sensitization of students is necessary during formal software project management courses. In addition, psychology may be incorporated into software project management curricula and this is confirmed by Cook (2004) who stated the need for project managers to have a clear grasp of social psychology to insure optimum performance of project teams. According to Taylor (as cited in Heikkila, 2002), one has to see beyond technical capabilities and recognize the value of businessfocused skills in order to successfully oversee and manage an IT department.

\section{Soft Skills Dimensions}

A plethora of soft skills dimensions has been identified for the management of projects (Belzer, 2004; Moreira, 2004). These soft skills include, amongst others, communication skills, team building skills, flexibility and creativity skills, leadership skills and the ability to manage stress and conflict. Moreover, a number of research initiatives are underway to sensitize stakeholders and project managers regarding the importance of such skills to achieve smooth execution of projects. Software projects, in particular, warrant a careful selection of project managers to achieve project objectives.

Mazarr (2000) mentioned that human beings know more that just "rote, mechanical operations and endless repetition of tasks" and he observed that the best workplaces are filled not by those with the most intimidating technical knowledge but rather by those with the best soft skills.

\section{Communication skills}

Communication skills refer to the ability to convey ideas easily and clearly in order to ensure that the team moves towards a common goal (Belzer, 2004). Effective communication is a very important soft skill required by software project managers. According to Belzer (2004), "project managers must have the ability to convey complex ideas easily, clearly articulate what must be accomplished, keep the team moving towards a common goal, foster an environment that allows team members to communicate openly and honestly, admit their own mistakes without losing respect, negotiate, listen and facilitate". It is generally agreed that effective communication is the key to the success of any endeavor in which people are involved. The IT field is no exception, especially where software development is concerned. Very often, aspects such as language, learning styles, communication networks, preferred learning mode, memory access and retrieval systems, attention and retention, and various other factors affecting learning; information processing and communication are simply disregarded. Particularly, within the ambit of the IT domain, these aspects are minimized in favor of technology (Newstrom \& Davis, 2001).

Many managers have now started to accept and appreciate the importance of NLP (Neuro Linguistic Programming) in the learning process, and in establishing effective communication patterns in, and between, organizations. One cannot deny the fact that the success of any project rests upon the judicious management of all information. Hence, the importance of a proper communication network, and various related aspects should be carefully considered, to ensure the success of projects where people are involved (Newstrom \& Davis, 2001).

Throughout the software development process, communication of project information should be encouraged. Consideration has to be given to who needs what information, in what format and when (Bruce and Langdon, 2000). Two-way communication must be enhanced, thereby, inviting important feedbacks to keep projects moving in the right direction. In this way, the software project manager may also encourage the project team to be open and honest. The software project manager must ensure that team members are not intimidated by fear for repercussion (Bruce $\&$ Langdon, 2000). 
Various means of communication like formal meetings, informal discussions and reports etc., must be encouraged. Also, the use of email may be an extremely useful time-saving device and the use thereof should be considered.

\section{Team building}

Team building involves the setting up of a team with an appropriate mix of skills to ensure the successful completion of a project. Conflicting behavior between team members should be detected as early as possible. Software project management is typically a team activity, and it is groups of people working together formally that can guarantee the achievement of defined objectives related to software project management. Teamwork is very significant to project management as there is a clear need for considerable interaction between people carrying out different functions, but with a common purpose.

Team work is important at various levels - from senior management level down to and including lower levels. Different types of teams are necessary: inter-disciplinary teams, informal teams, autonomous teams, and others, during the various phases of a project. The collection of individual skills working towards a common goal constitutes a powerful force (Phillips, 2002). The effect is that "The whole is greater than the sum of the parts", as Gray \& Larson (2000) rightly pointed out.

Hence, team building and team development will be the manager's responsibility. The project manager will have to ensure and encourage individuals to join teams and create situations to promote effective teamwork. Once in place, the teams should be involved in team processes and carry out their tasks and maintenance functions (Newstrom \& Davis, 2001).

Team building helps establish group norms, group behavior and desired attitudes and group identity. Software project managers should ensure that a full complement of people with a commensurate level and mix of skills and personalities are adequately represented on a project (Bruce \& Langdon, 2000). Software project managers may seize the opportunity of project review meetings to strengthen teamwork and help build team confidence.

\section{Flexibility and creativity}

Since every software project has unique characteristics, each may call for a different combination of components, templates, tools and techniques (Belzer, 2004). The software project manager must also adapt to the needs of the project. Flexibility and creativity can be promoted through the understanding of the personality of individual members, and acceptance of individual preferences (Santrock, 2000).

The use of toolkits and other equipment is possible through an appreciation of the intellectual abilities of the team members and the belief that each and every individual is perfectible. Opportunities provided by the software project leader to the team will help members to initiate actions and encourage creativity.

\section{Leadership}

According to Dobbins and Pettman (1997), leadership is the ability to motivate people to work towards achieving common goals, to make ordinary people display extraordinary performance. In short, leadership has been related to a person's skills, abilities and degree of influence to get people moving in a direction, making decisions and doing things that they would normally not have embarked on. Leading is one of the functions of managers and as such software project managers must lead a software project team. Different styles of leadership, some better than others in certain circumstances, are adopted by software project managers. Good teamwork may result from consensus building between project managers and team members rather than adopting a dictato- 
rial style. A software project manager should be someone whom people want to seek out rather than avoid (Bruce \& Langdon, 2000). According to Bruce \& Langdon (2000), four leadership styles (as per table 2 below) may be associated with software project managers.

Table 2 - Leadership styles

\begin{tabular}{|l|l|}
\hline \multicolumn{1}{|c|}{ Leadership style } & \multicolumn{1}{c|}{ Description } \\
\hline Dictatorial & $\begin{array}{l}\text { This style refers to the decision-making process by the project manager } \\
\text { alone. The latter displays autocratic and controlling characters. This } \\
\text { style may be adopted when the project faces a crisis and when there is } \\
\text { no time for consultation between the project manager and individuals } \\
\text { concerned with the project. The dictatorial style must be used with care } \\
\text { and as infrequently as possible since it demotivates the team members, } \\
\text { thereby discouraging teamwork. }\end{array}$ \\
\hline Analytic & $\begin{array}{l}\text { The project manager reaches a decision by gathering and analyzing } \\
\text { facts. This style, which requires good analytical skills, is adapted when } \\
\text { a project is running short of time and the correct decision must be taken } \\
\text { quickly. }\end{array}$ \\
\hline Opinion-seeking & $\begin{array}{l}\text { This style involves gathering team members' opinions in order to reach } \\
\text { a decision. Team confidence is built and the project manager indicates } \\
\text { that the views of the team are valued positively. }\end{array}$ \\
\hline Democratic & $\begin{array}{l}\text { This style refers to team participation encouragement and involvement } \\
\text { in the decision-making process. It motivates the team and helps } \\
\text { strengthen their commitment to the project. }\end{array}$ \\
\hline
\end{tabular}

Recent work performed in the domain of leadership highlights the importance of emotional intelligence as one of the basic requirements of the modern leader (Goleman, 1997). The behavior of human beings is influenced by emotions since the dawn of time. Many theorists have emphasized the importance of emotions and how to deal with emotional employees and it is nowadays widely accepted that the management of emotions, particularly anger, can assist in stress management. Goleman (1998b) argues that stress can be considered as the most damaging and costly illness in most organizations.

The psychological implications in the choice of an appropriate leadership style cannot be overlooked. The contingency leadership style, considered as the most popular among employees is, however, not generally acceptable to all managers. Many prefer to adopt one particular style and rarely accept change, usually to the detriment of the employee.

Emotional intelligence, leadership styles and human resource management are some of the key issues that need to be considered as desirable soft skills indispensable for successful IT project management.

\section{Organizational effectiveness}

To organize is the management function that focuses on arranging and allocating work, authority and resources among an organization's members so that plans may be successfully carried out (University of Mauritius, 2004). Effective organizations are learning organizations. A learning organization takes an institutional permanence, and acceptable modes of behavior become selfevident to its members. Such shared meaning held by members of the organization contributes to the establishment and reinforcement of organizational culture. With the advent of IT, several characteristics that capture the essence of organizational culture have become more evident. As such, aspects such as innovation and risk taking, attention to detail, people orientation, team orientation, outcome orientation, stability, positive aggressiveness and other dimensions which di- 
rectly or indirectly affect individual members should be given due consideration (Farago \& Skyrme, 1995).

One should be cognizant of the fact that organizational culture has several important functions. An organization with a dominant culture defines the boundary which limits the behavior of its members; it conveys a sense of identity among its members; it facilitates the generation of commitment; it enhances internal social system stability and helps hold the organization together; it also serves as a sense-making and control mechanism; and it guides and shapes the attitude and behavior of the members of the organization (Farago \& Skyrme, 1995). It is therefore important for software project managers to understand the corporate culture, the organizational dynamics and the individual they are dealing with (Belzer, 2004).

\section{Stress management}

Stress refers to pressure, tension or worry resulting from problems (Oxford Advanced Learner's Dictionary, 1999). Stress management is necessary for the software project manager who has to perform under pressure quite often and must not be overwhelmed to the extent that the team is also affected by their behavior. A certain level of stress is important for the software project manager to perform well and this type of stress is called eustress, which is good stress. When stress becomes excessive, it can cause harm to oneself or to the immediate surroundings. Beyond a certain level, it can cause distress.

Distress can be harmful to the extent that it can lead to the following problems that may affect one's health and at the same time hamper progress of the project:

- Physical problems like pain, tiredness, colds, insomnia, dizziness, nausea, palpitations and sweating.

- Emotional problems like anxiety, guilt and lack of control, anger, depression, pessimism, irritability, irrational fears and resentment.

- Mental problems like poor memory and concentration, negative thoughts, confusion and loss of sense of humor. Stress sufferers can lose up to $50 \%$ of their aptitude to perform their jobs (Chapman, 2001).

- Behavioral problems like smoking, crying, fidgeting, alcoholism, lashing out and shouting.

Software development is an area where constraints of deadlines, degrading quality of work and budget overrun can rapidly lead to a degeneration of the working environment. Distress will definitely cause a deterioration of the situation. Maintaining a good level of eustress as early as possible and ensuring that it does not turn into distress can help to improve the progress of the project.

\section{Time management}

According to PMI (2000), time management includes the processes required to ensure timely completion of projects. The soft skills side of time management refers to the ability of the software project manager to plan, delegate, organize, direct, and control.

These attributes can be improved through experience. A list of obstacles preventing effective time management has to be prepared (a so-called list of time wasters) and ways to eliminate these time wasters should be established and applied. 


\section{Change management}

Changes are inevitable during the execution of a project and some circumstances may cause the team to feel demotivated. It is, therefore, necessary to adjust the plan accordingly to accommodate changes. Some changes are within the control of the software project manager (like shortening the time schedule) while others are not (like the transfer of one key team member to another project by senior management). In this situation, an assessment of the impact must be made with regards to changes to schedules, budgets and resources involved. Any alteration should be identified and evaluated before committing changes (Proehl, 2001).

One important change management issue is dealing with user resistance. Especially, in the field of software projects, changes are inseparable features as new developments in technology are brought about continually. Both users and team members have to be informed as early as possible. People's concerns need to be taken into consideration and actions to dissipate their fears have to be taken as expeditiously as possible (Proehl, 2001).

In particular, user resistance can cause a software project to fail at the last stage (operational stage) after months or years of assiduous effort. Therefore, this issue has to be taken care of from the outset of the project. One solution is to involve the users throughout the different software project phases (James, 1999).

\section{Trustworthiness}

Trustworthiness is the value given to the belief that one can rely on the goodness, strength and ability of someone else (Oxford Advanced Learner's dictionary, 1999). Trust is the basic requirement that can ensure the success of any human enterprise. Trust must prevail at all times between partners and between the manager and his/her subordinates. All relationships ought to be based on trust.

Mutual trust must prevail throughout the project execution between the software project manager and all of the stakeholders involved in the project. Simply meeting deadlines is just one facet of the objectives of a project; a software project manager must also be able to convey that he/she can always be trusted to do what is right at the right time to render the project successful and the client satisfied (Lussier, 1990).

\section{Conflict management}

Conflicts are serious disagreements that emerge within the project team during the execution of a software project. They may arise due to disagreements over priorities, allocation of resources, quality of work (Gray \& Larson, 2000) or other reasons. Conflicts may be desirable (especially, when they clear ambiguities or when they raise concerns about a certain problem or pitfall) or can hinder the performance of a project (e.g. when both parties in conflict are wrong in the debate concerned). Desirable conflicts are often referred to as functional conflicts while undesirable conflicts are also called dysfunctional conflicts.

Conflict resolution skills are necessary for a software project manager to prevent behaviors of team members from degenerating into irreconcilable situations that may prohibit them from ever working together productively again (Newstrom \& Davis, 2001).

Dysfunctional conflict resolution is a challenging task for software project managers. It might not be identified until it becomes too late to overcome. According to Gray \& Larson (2000), the following strategies can be employed to manage it: 
- Mediation of conflict

This strategy relies on convincing the parties concerned about the need for making concessions in the interest of the project. The project manager has to negotiate the resolution by using reasoning, persuasion and suggesting alternatives.

- Arbitration of conflict

A solution is sought that allows each party to save face.

- Control of conflict

The conflict is controlled by reducing its intensity either by smoothing over the differences or postponing the resolution to a more suitable period after both parties regained composure. In case no solution can be found, project assignments may have to be rearranged so that the persons concerned are not allowed to interact any further.

- Accepting conflict

Sometimes the software project manager may have to accept the conflict through the life of the project but must introduce distractions to ignore the issue.

- Elimination of conflict

Conflicts may escalate to the point that they become intolerable and unacceptable. In such cases, the person at fault must be removed from the project. Software project managers must constantly watch out for behaviors within the project team that may escalate into conflict. The ability to read body language to identify unspoken disagreements may be an important skill for project managers.

\section{Integrating Soft Skills and Hard Skills in Software Project Management}

The high failure rate of software projects necessitates actions to be taken as soon as possible in order to improve this discipline. In this context, it is imperative to integrate soft skills along with hard skills in existing and emerging software project management methodologies.

The previous sections provide details about some important soft skills required by software project managers. More soft skills attributes for project managers are embodied in the emotional intelligence framework put forward by Goleman (1998a) and recapitulated by Barry and Du Plessis (2004).

Soft skills attributes of the software project manager that require a high level of activation during the different phases of a project have to be defined and then considered at the right time. A table of activation of soft skills, considered in the previous sections, for different phases of software projects may be prepared as shown in Table 3:

Table 3 - Soft skills activation

\begin{tabular}{|l|c|c|c|c|c|}
\hline \multirow{2}{*}{ Soft Skills } & \multicolumn{5}{c|}{ Project management phases } \\
\cline { 2 - 6 } & Initiating & Planning & Executing & Controlling & Closing \\
\hline $\begin{array}{l}\text { Communication } \\
\text { skills }\end{array}$ & & & $\sqrt{ }$ & $\sqrt{ }$ & $\sqrt{ }$ \\
\hline Team building & & & $\sqrt{ }$ & & \\
\hline $\begin{array}{l}\text { Flexibility and } \\
\text { creativity }\end{array}$ & $\sqrt{ }$ & $\sqrt{ }$ & $\sqrt{ }$ & & \\
\hline Leadership & & & $\sqrt{ }$ & $\sqrt{ }$ & \\
\hline
\end{tabular}




\begin{tabular}{|l|c|c|c|c|c|}
\hline \multirow{2}{*}{ Soft Skills } & \multicolumn{5}{|c|}{ Project management phases } \\
\cline { 2 - 6 } & Initiating & Planning & Executing & Controlling & Closing \\
\hline $\begin{array}{l}\text { Organizational } \\
\text { effectiveness }\end{array}$ & $\sqrt{ }$ & $\sqrt{ }$ & & \\
\hline $\begin{array}{l}\text { Stress Man- } \\
\text { agement }\end{array}$ & & $\sqrt{ }$ & $\sqrt{ }$ & & \\
\hline $\begin{array}{l}\text { Time Manage- } \\
\text { ment }\end{array}$ & & $\sqrt{ }$ & $\sqrt{ }$ & \\
\hline $\begin{array}{l}\text { Change Man- } \\
\text { agement }\end{array}$ & & & $\sqrt{ }$ & $\sqrt{ }$ & \\
\hline Trustworthiness & & & $\sqrt{ }$ & $\sqrt{ }$ & \\
\hline $\begin{array}{l}\text { Conflict Man- } \\
\text { agement }\end{array}$ & & & & & \\
\hline
\end{tabular}

Table 3 was compiled by means of interviews conducted with project managers/systems analysts of various software development organizations. However, in-depth research is required so that the appropriate soft skills may be added and other skills excluded depending on the circumstances prevailing in an organization, culture or country. The software project manager is required to be conscious of a summary of skills necessary at the right time.

\section{Conclusion}

It is generally well known that software projects suffer from failure to meet deadlines, cost overruns and leave customers disillusioned. Substantial effort has been made in the area of hard skills comprising processes, tools and techniques. Project management methodologies are being developed and improved, but still a large number of projects do not live up to expectations.

Apart from hard skills, research in the area of soft skills is very promising. Belzer (2004) mentioned that a greater piece of the puzzle for the successful delivery of projects, and in particular software projects, is that of soft skills. Companies like Mastek, Polaris and Sun Microsystems have incorporated such skills into their training agenda (Arora, 2003). A range of soft skills attributes required by a software project manager has been identified. The emotional intelligence framework proposed by Goleman (1998a) provides a number of soft skills dimensions that can improve software project success.

Alternatively, a table of soft skills, such as table 3 may be prepared to emphasize the skills required at various stages of the project in execution. This table could require further research, as it might not include the same soft skills for every organization, culture or regional setting. Furthermore, an empirical study as the one carried out at the University of Arkansas may be used as a starting point towards the accommodation of soft skills in software project management.

The soft skills required at different phases of a software project development life cycle need to be identified and the experienced software project manager has to be aware about the right time to make use of such skills. The soft skills, deemed important for software projects, have to be carefully selected and taken into consideration through the life cycle of a project. A simple framework has been proposed for an activation of the necessary soft skills during various phases of a software project. Accommodating soft skills in software project management can overcome some shortcomings in existing software project management methodologies. Therefore, greater research efforts should be expended to accommodate soft skills in software project management to improve success of the resulting projects. The outcome of these efforts may ensure greater customers satisfaction, motivate software project teams and exceed stakeholders' expectations. 


\section{References}

Arora, S. (2003). Soft skills training: Outsourced vs. in-house. Retrieved February 03, 2005, from http://www.expressitpeople.com/20040426/cover.shtml

Barry, M. L. \& Du Plessis, Y. (2004). An investigation into emotional intelligence as an important attribute for project managers. Proceedings of the 2004 PMSA Global Knowledge Conference, Johannesburg, South Africa, 320-329.

Belzer, K. (2004). Project management: Still more art than science. Retrieved August 19, 2004, from http://www.pmforum.org/library/papers/BusinessSuccess.htm

Bruce A. \& Langdon, K. (2000): Project management. New York: Dorling Kindersley.

Bupa, S. H. (2005). Why do so many major IT projects fail? Computer fraud \& security, 15-17.

Chapman, A. (2001). Stress management. Retrieved November 24, 2004, from http://www.businessballs.com/stressmanagement.htm

Cooke, R. (2004). Social psychology in project management. Retrieved August 23, 2004, from http://www.pmforum.org/library/papers/pmpsych1.htm

Dobbins, R. \& Pettman, B. O. (1997). Self-development: the nine basic skills for business success. Journal of management development, 16(8), 521.

Dorsey, P. (2000). Top 10 reasons why systems projects fail. Retrieved February 10, 2005, from http://www.dulcian.com/papers

Farago, J. \& Skyrme, D. (1995). The learning organization. Retrieved November 24, 2004, from http://www.skyrme.com/insights/3lrnorg.htm

Goleman, D. (1997). Emotional Intelligence. Why it can matter more than IQ. New York: Bantam Books.

Goleman, D. (1998a). Working with emotional intelligence. New York: Bantam Books.

Goleman, D. (1998b). What makes a leader? Harvard Business Review, 76(6), 93.

Gray, C. F. \& Larson E. W. (2000). Project Management: The managerial process. Singapore: McGrawHill.

Heikkila, P. (2002). Skills survey 2002. You're in IT-Should you do an MBA? Retrieved February 03, 2005, from http://comment. silicon.com/0,39024711,11032240,00.htm

Hughes, B. \& Cotterell, M. (2002). Software project management ( $3^{\text {rd }}$ ed.). London, UK: McGraw-Hill.

James, D. (1999). Managing people in organisations. Financial World Publishing.

Kirsch, L. J. (2004). Software project management: An integrated perspective for an emerging paradigm. Retrieved August 19, 2004, from http://www.pinnaflex.com/pdf/framing/CH15.pdf

Lussier, R.N. (1990). Human relations in organisations. Homewood, IL: Irwin.

Moreira, P. (2004). Soft skills for IT professionals. Retrieved August 26, 2004, from http://www.certmag.com/issues/jan01/dept techcareers.cfm

Newstrom, J. W. \& Davis, K. (2001). Organisational behavior: Human behavior at work. New York: McGraw-Hill.

Oxford Advanced Learner's Dictionary. (1999).

Phillips, J. (2002). IT project management. New Delhi, India: Tata McGraw-Hill.

PMI. (2000). A guide to project management body of knowledge. PMBOK® Guide. 2000 Edition.

Proehl, R. A. (2001). Organisational change in human services. UK: Sage Publication.

Santrock, J. W. (2000). Psychology (6th ed.). Congress Lib. 
Sonnekus, R. \& Labuschagne, L. (2004). Establishing the relationship between IT project management maturity and IT project success in a South African context. Proceedings of the 2004 PMSA Global Knowledge Conference, Johannesburg, South Africa, 183-192.

Sukhoo, A., Barnard, A., Eloff, M.M., \& Van der Poll, J.A. (2004a). Towards a framework for evaluating strengths and weaknesses of software projects. Proceedings of the 2004 PMSA Global Knowledge Conference, Johannesburg, South Africa, 193-199.

Sukhoo, A., Barnard, A., Eloff, M.M., \& Van der Poll, J.A. (2004b). A survey of project management tools, techniques and methodologies used in Mauritius: The current status. Proceedings of the 2004 PMSA Global Knowledge Conference, Johannesburg, South Africa, 320-329.

The Standish Group (2001). Extreme CHAOS. Retrieved August 25, 2004, from http://www.standishgroup.com/sample_research/PDFpages/extreme_chaos.pdf

Fowdar, R. R. R., Peerally, J. A., Boolaky, M., Baichoo, R., Lai Wah, D., Gokhool, D., Vencatachellum, I., \& Seebaluck, A. (2004). Organisation and management. Course manual. University of Mauritius.

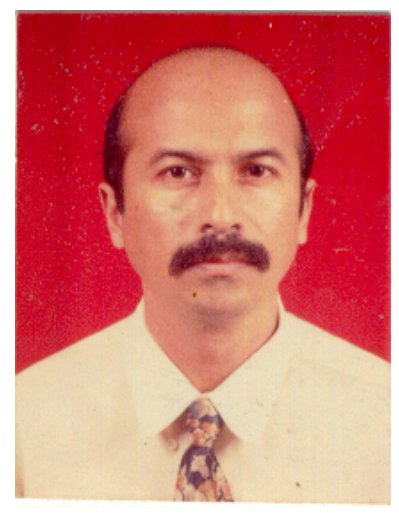

\section{Biography}

Aneerav Sukhoo, is a project manager working for the Ministry of Information Technology \& Telecommunications in Mauritius. He has 15 years of experience, out of which 8 years in IT project management, in dealing with implementation of IT projects in the Public Service.

He has a Honours Bachelor degree in computer Science from the University of South Africa and a Master of Information Technology degree from Charles Sturt University. He is presently preparing a $\mathrm{PhD}$ thesis at the University of South Africa for the development of a software project management methodology.

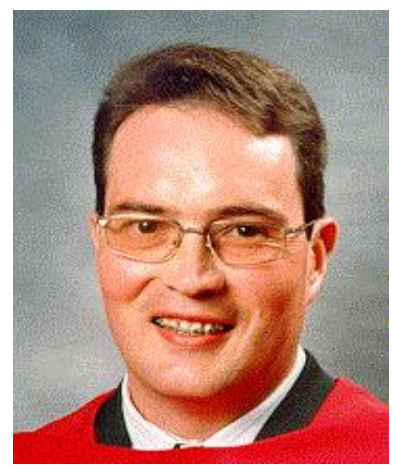

Andries Barnard, associate professor in the Department of Computer Science and Information Systems, holds a PhD (Computer Science). He teaches undergraduate courses in automata theory and formal languages and project management, as well as postgraduate courses in project management and research methodology. His research interests include computer ethics and graph grammar languages.

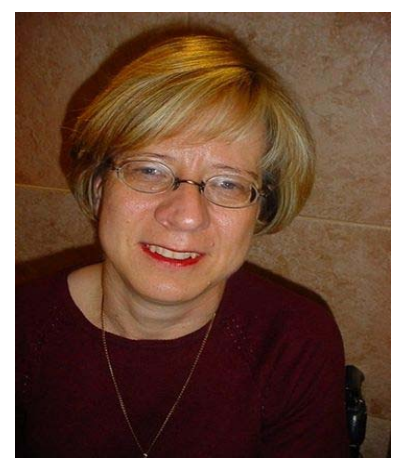

Mariki Eloff received a $\mathrm{PhD}$ Computer Science degree from the Rand Afrikaans University (RAU), South Africa. She has presented research papers at international and national conferences focusing on information security. She joined Unisa as an associate professor in the School of Computing during October 2002. She has assisted in the organization and management of international conferences in information security and has been part of the ISSA Conferences since its inception in 2000 . 
During 2001 she participated in information security management research projects under the joint leadership of RAU and the South African Bureau of Standards (SABS). She has also been engaged in the development of various information security-training modules for industry.

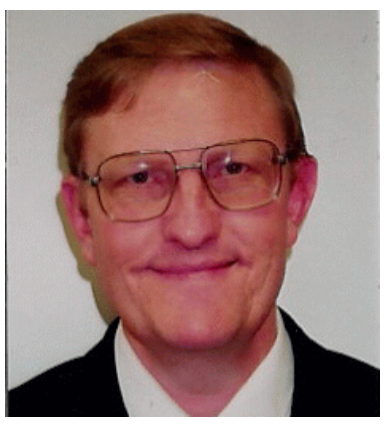

John A. Van der Poll is an associate professor and acting head of the Department of Systems Organisation in the School of Computing at the University of South Africa (UNISA). He holds a PhD in Computer Science and teaches an undergraduate course in operating systems, as well as postgraduate courses in compiler construction and formal program verification. His research interests are in formal specification languages and automated reasoning.

Mahendrenath Motah is senior lecturer at the University of Technology since 2000. He has extensive experience in the fields of Management, Administration, and Training at both national and international level. He has participated in various workshops, seminars and conferences at national and international level. He contributes to the local press and other media through articles and live programs. He has Master's degrees in Psychology and Ethnology, and a PhD in Arts and Human Sciences. He is also the Chairperson of the Regional Center for Urgent Anthropological and Ethnological Research (UNESCO, Vienna). 